\title{
Investigating Different Types of Red-Light Running Behaviors among Urban e-Bike Rider Mixed Groups
}

\author{
Fan Zhang $\mathbb{D}^{1,2}$ Chenchen Kuai ${ }^{1},{ }^{1}$ Huitao Lv, ${ }^{1,2}$ and Wenhao Li ${ }^{1,2}$ \\ ${ }^{1}$ School of Transportation, Southeast University, Dongnandaxue Road 2, Nanjing, Jiangsu, China \\ ${ }^{2}$ National Demonstration Center for Experimental Road and Traffic Engineering Education (Southeast University), \\ Nanjing 211189, China \\ Correspondence should be addressed to Chenchen Kuai; 213180126@seu.edu.cn
}

Received 22 April 2021; Revised 2 July 2021; Accepted 25 July 2021; Published 10 August 2021

Academic Editor: Tiziana Campisi

Copyright (C) 2021 Fan Zhang et al. This is an open access article distributed under the Creative Commons Attribution License, which permits unrestricted use, distribution, and reproduction in any medium, provided the original work is properly cited.

\begin{abstract}
The red-light running (RLR) behaviors of urban mixed e-bike groups (delivery and ordinary e-bike) have become the main cause of traffic accidents at signalized intersections. The primary purpose of this study is to identify influencing factors of e-bike riders' RLR behaviors, focusing on the role of delivery e-bike riders in mixed e-bike rider groups. Crossing behaviors of 4,180 e-bike samples (2006 delivery e-bikes and 2174 ordinary e-bikes) at signalized intersections are observed in Xi'an, China. The random parameter multinomial logit model is employed to capture the unobserved heterogeneous effects, and the effects of interaction terms are also considered. The results indicate that delivery e-bike riders are more likely to run red lights than ordinary e-bike riders. E-bike type, riders' age, waiting position, traffic volume, traffic light type, and time of day are associated with crossing behaviors in urban mixed e-bike groups. In addition, the variable of traffic light status is found to account for unobserved heterogeneity. Findings are indicative to the development of effective implications in improving e-bikes' traffic safety level at signalized intersections.
\end{abstract}

\section{Introduction}

Electric bikes (e-bikes), as an efficient mode of urban transportation, can not only facilitate the daily travel of urban dwellers but also effectively alleviate the traffic emission problem. The number of e-bikes in China was 250 million in 2018, with an average annual growth rate of more than $10 \%$ over the past decade [1]. However, the traffic safety of e-bikes has attracted extensive attention mainly because e-bike riders are more likely to participate in traffic violations, especially red-light running at signalized intersections [2-7]. Guo et al. compared red-light running behavior between e-bike and bicycle users [2] and found unobserved heterogeneities in the factors that influence red-light running rates [3]. Bai et al. compared and analyzed the traffic conflicts between e-bike riders and cyclists at signalized intersections and found that running red lights was the main cause of the conflict for e-bikes [4], and e-scooter riders were more likely to risk crossing the street [5]. Tang et al. analyzed e-bike riders' illegal crossing behaviors by obtaining data from questionnaires [6] and field shooting videos [7], respectively. Also, compared with the ordinary e-bike (OEB) riders, delivery e-bike (DEB) riders, as an emerging e-bike rider group under the booming of e-commerce in China, have gained extensive attention due to their high involvement in traffic violation behaviors at intersections [8]. There are at least 400 million delivery orders every week and around 7 million registered DEB riders in China $[8,9]$. Although DEB riders constitute a low proportion of the urban e-bike rider mixed groups than OEB riders, DEB riders have a higher cycling risk due to the higher daily cycling times, distance, and frequency of road crossing [10]. Besides, various delivery platforms force $\mathrm{DEB}$ riders to deliver as soon as possible within a limited time to occupy a larger market share, which causes the fact that they have to trade time for violating traffic lights [11]. DEB riders are five times more inclined to run red lights than OEB riders $[10,12]$, which leads to violent collisions with vehicles or 
pedestrians at signalized intersections [3, 4, 7, 10, 13]. Specifically, in the first half of 2017, there were 3,242 traffic accidents involving DEB riders in Nanjing, with 2,473 injuries and more than 110 traffic accidents that occurred among DEB riders in Shanghai $[9,10]$.

Additionally, waiting at signalized intersections during the red-light phase can affect travel time. Especially, the waiting time constitutes the extra delivery time for DEB riders, while the takeout platform fails to fully consider the blocking effect of the signal duration on the delivery process when designing the maximum delivery time [11]. Generally speaking, e-bikes and pedestrians share the same signal indicator, and the signal cycle can be divided into three stages: green signal, flashing yellow signal, and red signal. Crossing the road during a red-light time and starting cross the road during a flashing yellow-light time are both considered as RLR behaviors [14]. To analyze such two types of e-bike riders' crossing behaviors, we need to point out that red light violations may be different due to their demographic characteristics and cannot be grouped into one category [15]. Based on previous studies [13-17], red-light crossing behaviors of e-bike riders at signalized intersections could be classified into three types: running red lights immediately (IRLR), waiting and run red lights (WRLR), and not running red lights (NRLR). The definitions of these three types of behavior are as follows: IRLR refers to the behavior of ignoring the red light and directly crossing the intersection; WRLR behavior indicates that riders stop at the intersection for a while and eventually identify relatively safe gaps from the traffic flow to violate red light; and NRLR refers to the behavior of stopping because of observing the red light [13]. Particularly, it is crucial to distinguish IRLR and WRLR behaviors to understand the different levels of risk associated with different behaviors. The IRLR behavior is more dangerous than WRLR behavior because there is only less time left to effectively identify risks and take actions to avoid potential accidents [15]. Three different crossing behaviors not only affect cycling time but also affect the rider's actual crossing safety.

The factors affecting the tendency of violation behaviors and road accidents are usually divided into three types: individual, traffic, and road environment. Individual factor refers to the demographic and socioeconomic attributes. Traffic condition considers the influences of traffic volume, speed, and other traffic composition. Also, the road environment characteristics include the factors, e.g., geometrical design, road conditions, and traffic control [14]. The countermeasures based on the identified risk factors required to reduce the RLR of urban e-bike rider mixed groups may be different from those of other vehicles and pedestrians. Since this paper mainly studies e-bike riders' crossing behaviors, the following mainly is a review of literature research on riders. Previous studies have shown various factors affecting the riders' RLR behaviors $[1,2,5,7,11,12,14-25]$. In terms of individual characteristics, males are more likely to run red lights than females $[16,26]$. In addition, young and middle-aged cyclists are more likely to run red lights than older individuals $[4,8,12,17,18]$. Real-time traffic conditions also affect cyclists' crossing behavior; with the increase of conflict traffic volume, the probability of violating red light could decrease $[3,27,28]$. In other aspects, riders' waiting time at signalized intersections also has a significant impact on RLR behaviors. Waiting time over $30 \mathrm{~s}$ increases the RLR behavior probability during off-peak hours $[13,20]$. Regarding the signalized intersection design, the $\mathrm{T}$-intersection and the raised medians increase the probability of cyclists running red lights $[3,21]$. The geometry of the road also allows for these violations, especially the presence of a countdown signal $[2,20]$, while the road width and green ratio are negatively correlated with RLR behaviors [3]. Besides, environmental factors also affect riders' red-light violation behaviors. For example, the presence of riders waiting at the interactions could discourage other counterparts to run red lights $[15,18]$; cyclists waiting beyond the stop line are more prone to violate the traffic lights $[17,18]$. However, there are few studies on the crossing behavior of DEB rider groups. A recent study on delivery e-bikes' crossing behavior revealed that gender, visual search, and waiting position can significantly impact RLR behavior [1]. Heterogeneous differences in the influencing factors of RLR behavior between delivery and ordinary e-bike riders were also investigated [10].

To summarize, despite the abundant number of studies on traffic and environment factors that are influencing red light runners among various riders, we still have limited study on the RLR behavior of urban mixed e-bike rider groups. The influence mechanism of mixed groups' crossing behavior has not been thoroughly analyzed; especially, the role of $\mathrm{DEB}$ riders in the mixed groups is unclear. The objective of the current study is to investigate the characteristics and influencing factors of urban mixed e-bike rider groups' crossing behavior and explore the differences between $\mathrm{OEB}$ and DEB riders in crossing behavior and the effects of associated factors. The finding of this study might help provide effective solutions for improving the crossing safety level involving urban mixed e-bike rider groups at signalized intersections, especially in developing countries with high e-bike ridership.

\section{Materials and Methods}

In this section, we first introduce the data acquisition process, where the dependent variables are the three types of crossing behaviors of the e-bike riders and the independent variables are the observed rider attributes, behavior characteristics, signalized intersection characteristics, and traffic environment. Second, the modeling methods used are introduced, and the data flow chart is shown in Figure 1.

2.1. Data. Observation surveys were conducted at four signalized intersections in the downtown area of Xi'an, the largest city in northwestern China, at specific periods of weekday with good weather conditions in November 2019. Selected intersections should be as similar as possible in terms of road layout and geometric features and also have a high volume of nonmotorized traffic to ensure the generality 
of sampling (see Figure 2). The characteristics of the selected sites are shown in Table 1 (the two approaches of Jianshe Rd. \& Yanta N Rd. are recorded).

Considering that the peak delivery periods for DEB riders mainly focus on lunch and dinner, we filmed for a total of four hours at noon (11:00-13:00) and in the afternoon (17:00-1900, the travel peak of OEB riders) to capture more sample data of e-bikes crossing the street. There were no external interventions, such as traffic police, assistants, or enforcement camera, to interfere with riders' natural crossing behavior during the filming experiment in this study.

The e-bikes' crossing characteristics in the natural state are recorded based on video processing technology. The video can be played back repeatedly to check the data to ensure the accuracy of the sample information (see Figure 3). Video-based shooting technology has become a mainstream method and has been widely used in the study of nonmotorized traffic crossing behavior, including the risky behavior of e-bike riders at signalized intersections [5], the running red-light behavior of cyclists $[3,20]$, and the risky behavior of e-bikes and bicycles crossing the street $[13,25]$.

The data extraction process was performed manually by several trained graduate students who have been trained and tested separately prior to the formal data extraction. The training includes identifying different types of e-bikes and determining different crossing behaviors and crossing characteristics [28]. It is worth noting that when extracting the data, only the e-bikes directly crossing the intersections were coded; the e-bikes turning right (not regulated by the road traffic safety law) and turning left (restricted by the field vision of video) were not included [7]. In addition, DEB riders can be distinguished from OEB riders according to their uniforms, helmets, or delivery incubator in the back seat of e-bikes. A senior graduate research assistant was assigned to proofread and evaluate the data to ensure the validity of the data extraction. Demographic information (i.e., age and gender), e-bike type, e-bike activity, traffic volume, geometric design, traffic control, and signal timing are coded, and the descriptive statistics of the data is shown in Table 2. Among them, the gender and age (under 30 years old/over 30 years old) were determined by visually observing their dress preference, countenance, and posture [3, 28]. For traffic light status, the whole red-light cycle is divided into 3 stages according to the operation of the red light at the decile of red time $[20,22]$. The first two deciles are the early stage, the middle six are the middle stage, and the last two are the late stage (see Figure 4 for details). The signalized intersection characteristics include the signal characteristics (flashing signal or countdown signal), nonmotorized lane width, and crossing length (see Figure 3 for details). Regarding the traffic environment, the traffic volume is the number of vehicles in the conflict direction during the redlight cycle, and No. of individuals waiting upon arrival is the number of other individuals waiting for a green light when arrive. Besides, Cohen's Kappa was used for categorical variables, while the one-way intraclass correlation was used for continuous variables to ensure the reliability of data coding. All coefficients were between 0.8 and 0.95 .

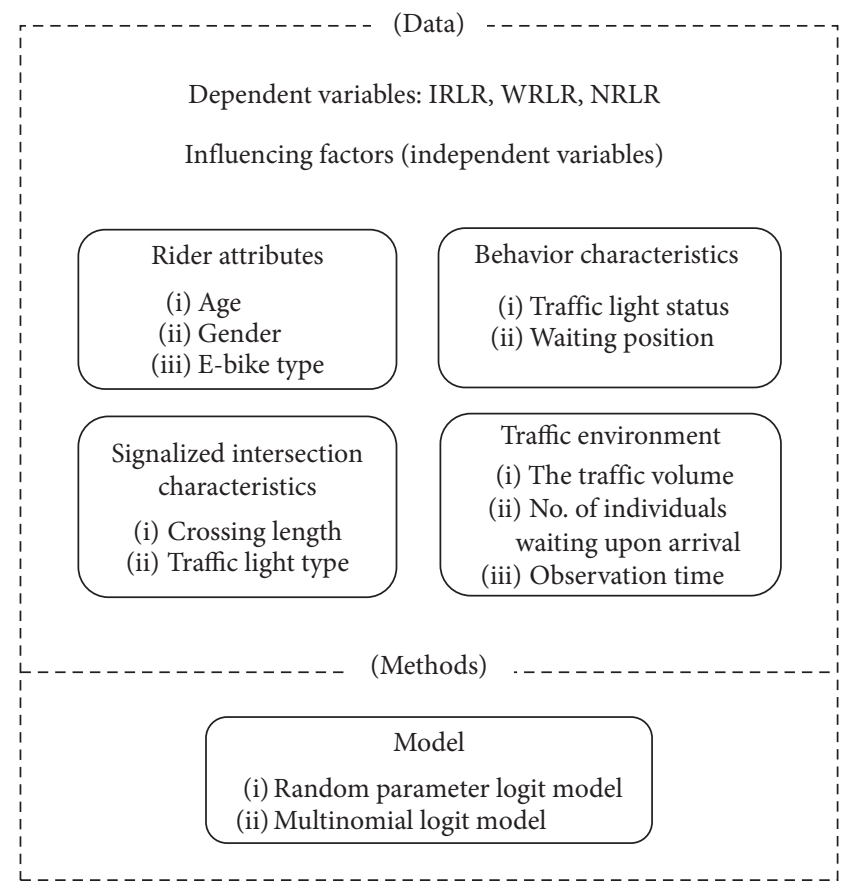

Figure 1: Data flow chart.

2.2. Analysis Method. Multinomial logit models are adopted to determine the probabilities of different crossing behaviors. Among them, the utility function of the model, i.e., the function that determines crossing behavior, is

$$
S_{\text {in }}=\beta_{i} X_{\text {in }}+\varepsilon_{\text {in }},
$$

where $S_{i n}$ is the utility function, $\beta_{i}$ denotes the vector of estimable parameters, $X_{i n}$ is a vector of the explanatory variables, and $\varepsilon_{\text {in }}$ is an error term [29]. This study developed a random parameter logit model to overcome the limitation of multinomial logit model, that is, the influence of variables on the crossing behavior is fixed among riders, as shown in the following formula [30]:

$$
P_{n}(i)=\int \frac{\exp \left[\beta_{i} X_{i n}\right]}{\sum_{i^{\prime} \in I} \exp \left[\beta_{i^{\prime}} X_{i n}\right]} f(\beta \mid \varphi) \mathrm{d} \beta,
$$

where $f(\beta \mid \varphi)$ refers to the density function of a certain distribution; its density function is described by the parameters set $\varphi$ of corresponding distribution, such as normal distribution $\varphi$ including the mean $\mu$ and standard deviation $\sigma$. As the probability function of random parameter logit model is nonclosed type, it cannot be solved directly by means of computer integration and the approximate solution needs to be obtained by computer simulation. Therefore, the Monte Carlo method is used to solve the random parameter logit model [31]. Halton sampling is adopted, which assumed that all variables' parameters to be estimated are random parameters and that they are normally distributed [32, 33].

The model is finally determined according to the characteristics of these parameters as well as some parsimony indices, including Akaike information criterion 




Figure 2: Field survey locations in the Xi'an city (the geographical background comes from AutoNavi).

TABLE 1: Intersection for field data collection.

\begin{tabular}{lcccc}
\hline Intersection & Crossing approaches & Signal type & $\begin{array}{c}\text { The red-light } \\
\text { length (s) }\end{array}$ & $\begin{array}{c}\text { Number of lanes in } \\
\text { both directions }\end{array}$ \\
\hline Youyi E Rd. \& Changsheng St. & Changsheng St. & Flashing & 36 & 2 \\
Jianshe Rd. \& Yanta N Rd. (1) & Jianshe Rd. & Flashing & 82 & 3 \\
Youyi E Rd. \& Wenyi Rd. & Wenyi Rd. & Flashing & 89 & 6 \\
Jianshe Rd. \& Yanta N Rd. (2) & Yanta N Rd. & Flashing & 99 & 7 \\
Zhuque St. \& Xiaozhai W Rd. & Xiaozhai W Rd. & Countdown & 114 & 8 \\
\hline
\end{tabular}

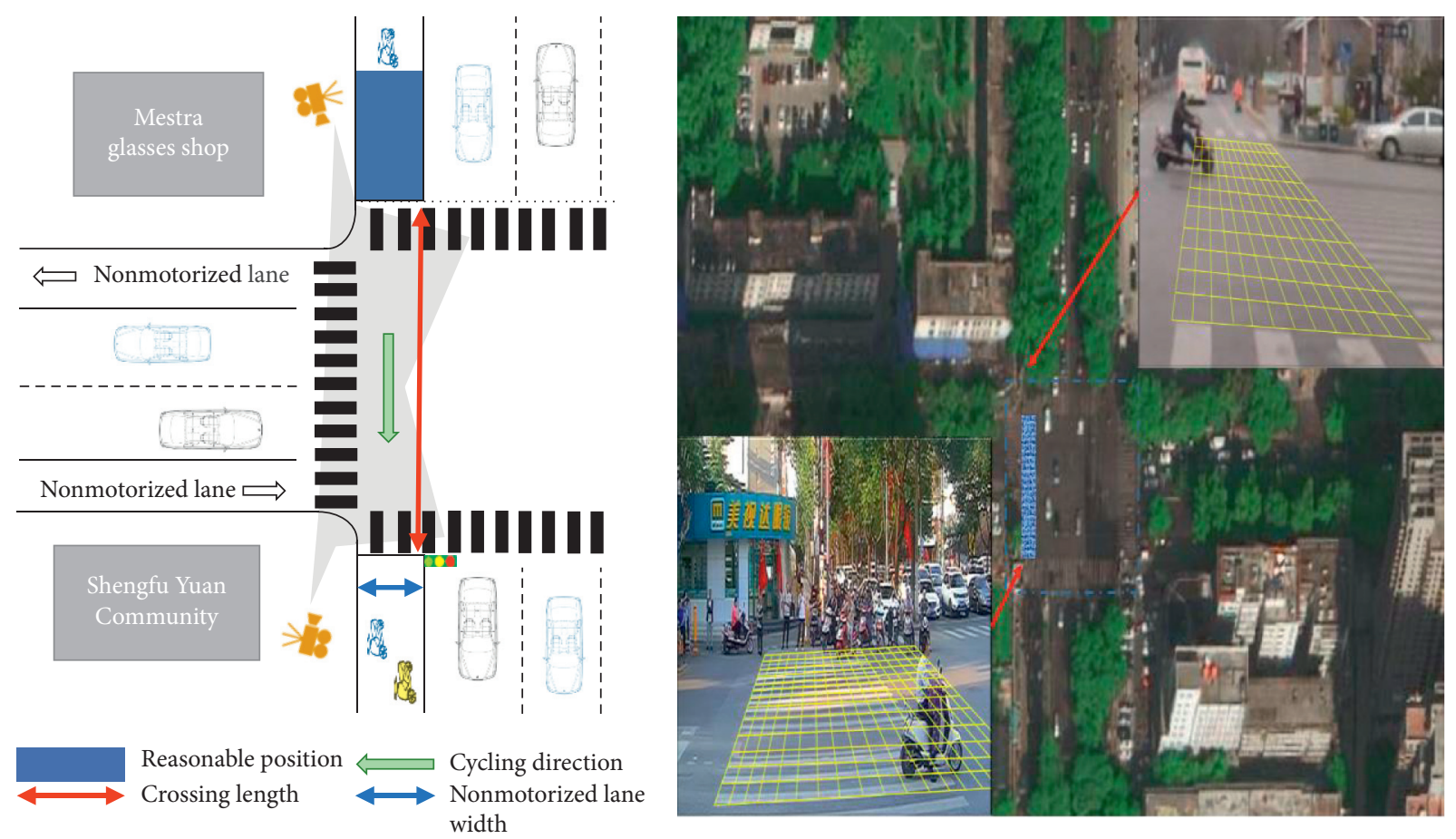

FIGURE 3: Schematic diagram of signalized intersection shooting (Zhuque St. \& Xiaozhai W Rd.). The basemap of the right half is from AutoNavi, and the two screenshots are taken from the roadside cameras. 
TABLE 2: Descriptive statistics of explanatory variables.

\begin{tabular}{|c|c|c|c|c|c|}
\hline \multirow{2}{*}{ Variable } & \multirow{2}{*}{ Attributes } & \multicolumn{3}{|c|}{ Crossing behaviors (percentage) } & \multirow{2}{*}{ Total } \\
\hline & & NRLR & WRLR & IRLR & \\
\hline \multirow{2}{*}{ Age } & Young & $693(43.0 \%)$ & $547(33.9 \%)$ & $372(23.1 \%)$ & 1612 \\
\hline & Older & $1409(54.9 \%)$ & $752(29.3 \%)$ & $407(15.8 \%)$ & 2568 \\
\hline \multirow{2}{*}{ Gender } & Female & $419(63.3 \%)$ & $175(26.4 \%)$ & $68(10.3 \%)$ & 662 \\
\hline & Male & $1683(47.8 \%)$ & $1124(32.0 \%)$ & $711(20.2 \%)$ & 3518 \\
\hline \multirow{2}{*}{ E-bike type } & Delivery e-bike & $842(42.0 \%)$ & $705(35.1 \%)$ & $459(22.9 \%)$ & 2006 \\
\hline & Ordinary e-bike & $1260(58.0 \%)$ & $600(27.6 \%)$ & $314(14.4 \%)$ & 2174 \\
\hline \multirow{3}{*}{ Traffic light status } & The early stage of the red light & $198(22.3 \%)$ & $271(30.5 \%)$ & $419(47.2 \%)$ & 888 \\
\hline & The middle stage of the red light & $1320(55.0 \%)$ & $846(35.2 \%)$ & $236(9.8 \%)$ & 2402 \\
\hline & The late stage of the red light & $584(65.6 \%)$ & $188(21.1 \%)$ & $118(13.3 \%)$ & 890 \\
\hline \multirow{2}{*}{ Waiting position } & Reasonable position & $1718(81.2 \%)$ & $353(16.7 \%)$ & $45(2.1 \%)$ & 2116 \\
\hline & Unreasonable position & $384(18.6 \%)$ & $952(46.1 \%)$ & $728(35.3 \%)$ & 2064 \\
\hline \multirow{2}{*}{ Traffic light type } & Flashing signal & $1624(49.5 \%)$ & $984(30.0 \%)$ & $671(20.5 \%)$ & 3279 \\
\hline & Countdown signal & $478(53.1 \%)$ & $315(35.0 \%)$ & $108(11.9 \%)$ & 901 \\
\hline \multirow{2}{*}{ Observation time } & Noon & $920(43.6 \%)$ & $705(33.4 \%)$ & $485(23.0 \%)$ & 2110 \\
\hline & Afternoon & $1182(57.1 \%)$ & $600(29.0 \%)$ & $288(13.9 \%)$ & 2070 \\
\hline
\end{tabular}

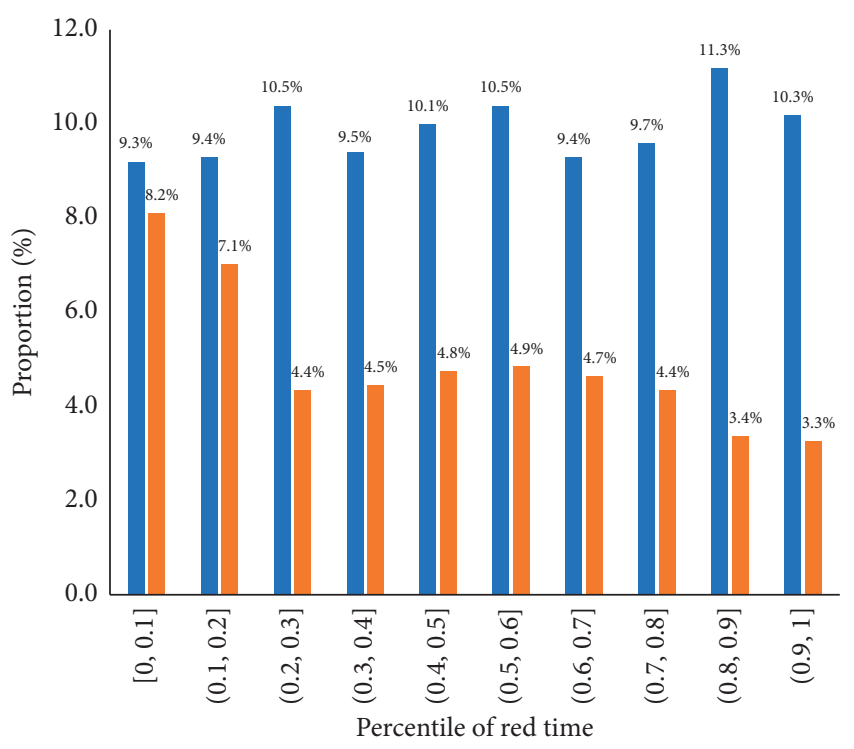

- Riders arrived in this red-light deciles

- RLR riders

FIGURE 4: The proportion of riders arriving in each decile of red time and the corresponding riders who running red-light during the entire red-light period (not restricted to certain arrival decile). Note: It can be seen that about $80 \%$ riders who arrived in the first two deciles perform RLR behavior during the entire red-light period, and the RLR rates of riders who arrived in the last two deciles were lowest.

(AIC), which consider both the goodness-of-fit and model complexity. AIC can be specified as follows:

$$
\mathrm{AIC}=-2 \ln (L)+2 K,
$$

where $L$ is the maximum likelihood function and $K$ refers to the number of parameters in the model.

To further analyze the comparative statistical superiority of these approaches, log-likelihood convergence and likelihood-ratio tests are used to compare these models (the basic model and the refined model). Likelihood-ratio tests (Equation (4)) were conducted to evaluate the relative statistical superiority of different specifications [31].

$$
\chi^{2}=-2\left[L L\left(\beta_{1}\right)-L L\left(\beta_{2}\right)\right]
$$

where $\beta_{1}$ and $\beta_{2}$ are the log-likelihoods at the convergence of the competitive models 1 and 2 , respectively. $\chi^{2}$ is the chisquare distributed with degrees of freedom equal to the difference in the number of estimable parameters between the competitive models.

Elasticity analysis is conducted in this study to quantify the effects of significant variables on the probabilities of different types of crossing behaviors. As shown in Table 2, all observed variables are indicator variables, where pseudoelasticity can be calculated as [31]:

$$
E_{X_{\text {in }}}^{P_{n(i)}}=\frac{P_{n}\left(i \mid X_{\text {in }}=1\right)-P_{n}\left(i \mid X_{\text {in }}=0\right)}{P_{n}\left(i \mid X_{\text {in }}=0\right)} .
$$

The pseudoelasticity of a variable specific to the crossing behavior choice outcome represents the percentage change in the probability of the crossing behavior choice category when the variable changes from 0 to 1 . Since it is calculated for each observed value, the average pseudoelasticity (APE) for each variable in the entire database is calculated and presented.

\section{Results}

The RLR rates of ordinary e-bikes, delivery e-bikes, and mixed groups are $42 \%, 58 \%$, and $49.7 \%$, respectively (see in Table 2). It can be seen that the addition of delivery e-bikes improves the RLR rate of the whole urban e-bike mixed groups. In this study, we identified the influencing factors associated with different RLR behaviors using the basic multinomial logit model and random parameter logit model, which considered and excluded the possible interaction effects between e-bike type and other influencing factors, respectively. Before determining the association, we 
performed a multicollinearity test to ensure that the initial variables were not highly correlated. First, we separately estimated all the potential contributing factors (basic model). Then, we considered the interaction effects of e-bike type on the association with significant factors (refined model). Therefore, four models were calibrated in the end. All possible candidate factors were screened, and only those contributing to crossing behaviors were included in the final models at the $5 \%$ significance level.

The goodness-of-fit measures of the proposed models are given in Table 3. Compared with the multinomial logit models, random parameter logit models are superior in lower likelihood-ratio test results and AIC values. The parameter estimation results obtained from random parameter logit models were present in the following section.

The estimation results of the basic model with no interaction effect are presented in Table 4, and the APE results are displayed under each corresponding variable. A total of 17 parameters are estimated to account for the influence of 10 variables on riders' crossing behavior choice outcomes. The e-bike type variable, delivery e-bike, is found to increase the probability of running red lights, which is supported by the significant positive estimates (34\% for WRLR and 65\% for IRLR). Two variables of behavior characteristics are found to significantly affect riders' RLR behaviors. Arriving at the middle and last stages is more likely to perform NRLR behavior than that at the early stage. The unreasonable waiting position variable is also found to increase the probability of IRLR behavior $(48 \%)$. In terms of signalized intersection characteristics, the probabilities of WRLR and IRLR behaviors get a $6 \%$ increase by countdown signal, and the probability of IRLR behavior reduces $9 \%$ as the crossing length increases one unit. Regarding the traffic environment, the probabilities of riders performing NRLR and WRLR behaviors increase 2\% by the traffic volume. Also, the number of riders waiting upon arrival is positively correlated with crossing behaviors ( $-6 \%$ for NRLR, $8 \%$ for WRLR, and $-6 \%$ for IRLR). Afternoon is significantly related to the NRLR behavior $(18 \%)$.

The parameter estimation results of the refined model are shown in Table 5. Since the parameter estimation results of Model 1 and Model 2 are similar, here, only the intervention effects of e-bike type in the refined model are discussed. Interactions between (i) DEB and age (34\% for NRLR and WRLR, $-21 \%$ for IRLR), (ii) DEB and time of day ( $58 \%$ for NRLR, $-12 \%$ for WRLR and IRLR), and (iii) DEB and waiting position ( $-6 \%$ for NRLR, $15 \%$ for WRLR and IRLR) on the probability of RLR behaviors are added.

\section{Discussion}

The influencing factors of RLR behaviors among urban mixed e-bike groups (DEB and OEB riders) are investigated in this study. For different types of crossing behavior, the significant factors are also different. Regarding rider attribute variables, DEB riders have higher probabilities of IRLR and WRLR behaviors than OEB riders. One possible explanation is that DEB riders need to deliver the order within the specified time, which makes it more demanding on delivery time $[8,9,12]$. The older riders are more cautious than youngers, which is consistent with the previous studies $[1,10]$. In addition, riders who arrive in the middle and late red-light stages are less likely to run red lights than riders who arrive at the early stage, and it is not hard to understand that riders who arrive early may not have the patience to wait long time enough. The last stage variable has a random effect on NRLR behavior $(1.43,1.26)$, that is, $87.2 \%$ of riders arriving at the last stage have an increased probability of not running red lights, while the remaining $12.8 \%$ have an increased probability of running red lights. Possible reasons for the heterogeneity of latearriving riders could be attributed to the effect of the social influence, such as failing to stop at red light when arriving alone at intersections $[10,15]$.

For signal intersection characteristics and traffic environment, the parameter estimation results of most variables are consistent with previous studies [3, 17-20, 28]. It is worth noting that the red-light running behavior is divided into two types in this study, which further reinforces our understanding of traffic violations, rather than general belief that the RLR behavior is homogeneous. The effects of crossing length on WRLR and IRLR behaviors are opposite. Each unit of crossing length increases lead to a reduction in the probability of IRLR behavior by $12 \%$, while WRLR behavior increases by $9 \%$. The possible explanation is that when riders arrive at a longer crosswalk, they may not have enough gap time to cross and instead choose to wait for the right opportunity to cross the road. Similarly, the effect of traffic volume and No. of individuals waiting upon arrival on riders' crossing behaviors is similar to that of crossing length.

Furthermore, the purpose of this study is to identify influencing factors of e-bike riders' crossing behaviors, especially the role of delivery e-bikes in mixed e-bike groups, which is mainly discovered through the interactions term between the e-bike type and other factors. The interaction effects by the age and time of day on the association between DEB riders and RLR propensity are significant. Interestingly, the RLR propensity of DEB riders decreases when they are older riders and during afternoon peak hours. It implies that individual characteristics and environment conditions can moderate the safety perception and therefore the crossing behavior of DEB riders. As for the time of day, which can also reflect the variation of traffic volume, such phenomenon can be attributed to there is less road traffic volume at noon than in the afternoon, allowing riders to cross the intersection with ease [10]. Yet, the results also indicate that the unreasonable waiting position further increases the probabilities of IRLR and WRLR behaviors of DEB riders by $52 \%$ and $35 \%$, respectively. In fact, the unreasonable waiting position means illegal occupation of the road to some extent, which partially reflects their poor safety awareness and lack of accurate perception of the high risk of collision in unreasonable areas [34].

The findings of this study also help understand the risk factors related to the crossing behaviors of urban e-bike rider mixed groups. Therefore, the countermeasures can be 
TABLE 3: Goodness-of-fit measures for multinomial and random parameter models.

\begin{tabular}{|c|c|c|c|c|}
\hline & \multicolumn{2}{|c|}{ Basic model } & \multicolumn{2}{|c|}{ Refined model } \\
\hline & Multinomial logit & Random parameter logit & Multinomial logit & Random parameter logit \\
\hline AIC & 3188.4 & 3170.2 & 3172.9 & 3164.5 \\
\hline$L L(0)$ & -2203.82 & -2203.82 & -2203.82 & -2203.82 \\
\hline$L L(\mathrm{~B})$ & -1578.22 & -1568.1 & -1567.45 & -1562.25 \\
\hline Number of parameters & 16 & 17 & 19 & 20 \\
\hline & \multicolumn{2}{|c|}{20.24} & \multirow{2}{*}{\multicolumn{2}{|c|}{10.4}} \\
\hline Adjusted $R^{2}$ & 0.284 & 0.288 & & \\
\hline
\end{tabular}

TABLE 4: Random parameter logit model estimation results (no interaction).

\begin{tabular}{|c|c|c|c|c|c|c|c|}
\hline & & NRLR & AEP & WRLR & AEP & IRLR & AEP \\
\hline $\begin{array}{l}\text { Rider attributes } \\
\text { E-bike type } \\
\text { Age }\end{array}$ & $\begin{array}{c}\text { Delivery e-bike } \\
\text { Older }\end{array}$ & $\begin{array}{c}-0.56^{* *}(0.19) \\
-\end{array}$ & $\begin{array}{c}-54 \% \\
30 \% \\
\end{array}$ & $\begin{array}{c}0.48^{* *}(0.23) \\
-0.23^{* *}(0.11)\end{array}$ & $\begin{array}{c}34 \% \\
-53 \% \\
\end{array}$ & $\begin{array}{l}0.32^{* * *}(0.13) \\
-0.29^{* *}(0.14)\end{array}$ & $\begin{array}{r}65 \% \\
-40 \% \\
\end{array}$ \\
\hline Behavior characteristics & & & & & & & \\
\hline $\begin{array}{l}\text { Traffic light status } \\
\text { Waiting position }\end{array}$ & $\begin{array}{l}\text { The middle stage } \\
\text { The last stage } \\
\text { Std. dev. } \\
\text { Unreasonable position }\end{array}$ & $\begin{array}{c}- \\
1.17^{* * *}(0.20) \\
1.08^{* * *}(0.38) \\
-\end{array}$ & $\begin{array}{c}16 \% \\
24 \% \\
- \\
-15 \% \\
\end{array}$ & $\begin{array}{c}-0.42^{* *}(0.16) \\
- \\
- \\
2.01^{* * *}(0.19)\end{array}$ & $\begin{array}{c}-16 \% \\
-18 \% \\
- \\
34 \% \\
\end{array}$ & $\begin{array}{c}-1.73^{* * *}(0.19) \\
- \\
- \\
4.43^{* * *}(0.16) \\
\end{array}$ & $\begin{array}{c}28 \% \\
-18 \% \\
- \\
48 \% \\
\end{array}$ \\
\hline $\begin{array}{l}\text { Signalized intersection characteristics } \\
\text { Traffic light type } \\
\text { Crossing length }\end{array}$ & $\begin{array}{c}\text { Countdown signal } \\
-\end{array}$ & $\begin{array}{c}1.10^{* *}(0.32) \\
- \\
\end{array}$ & $\begin{array}{c}-5 \% \\
6 \% \\
\end{array}$ & $\begin{array}{c}-0.54^{* *}(0.22) \\
0.03^{* *}(0.01) \\
\end{array}$ & $\begin{array}{l}6 \% \\
6 \% \\
\end{array}$ & $-0.04^{* * *}(0.01)$ & $\begin{array}{c}6 \% \\
-9 \% \\
\end{array}$ \\
\hline $\begin{array}{l}\text { Traffic environment } \\
\text { The traffic volume } \\
\text { No. of individuals waiting upon arrival } \\
\text { Time of day }\end{array}$ & $\begin{array}{c}- \\
- \\
\text { Afternoon }\end{array}$ & $\begin{array}{c}0.12^{* * *}(0.03) \\
- \\
0.37^{* * *}(0.12)\end{array}$ & $\begin{array}{c}2 \% \\
-6 \% \\
18 \%\end{array}$ & $\begin{array}{l}- \\
- \\
-\end{array}$ & $\begin{array}{c}2 \% \\
8 \% \\
-5 \%\end{array}$ & $\begin{array}{c}- \\
-0.29^{* * *}(0.11) \\
-\end{array}$ & $\begin{array}{l}-3 \% \\
-6 \% \\
-5 \%\end{array}$ \\
\hline
\end{tabular}

The symbols ${ }^{*},{ }^{* *}$, and ${ }^{* * *}$ indicate significance at $10 \%, 5 \%$, and $1 \%$ levels, respectively.

TABLE 5: Random parameter logit model estimation results (with interaction effects).

\begin{tabular}{|c|c|c|c|c|c|c|c|}
\hline & & NRLR & AEP & WRLR & AEP & IRLR & AEP \\
\hline \multicolumn{8}{|l|}{ Rider attributes } \\
\hline E-bike type & Delivery e-bike & $-0.25(0.12)$ & $-67 \%$ & $0.43(0.15)$ & $28 \%$ & $0.31(0.11)$ & $44 \%$ \\
\hline Age & Older & - & $38 \%$ & $\begin{array}{c}-0.45^{* *} \\
(0.16) \\
\end{array}$ & $-17 \%$ & $-0.78^{* *}(0.24)$ & $-34 \%$ \\
\hline \multicolumn{8}{|l|}{ Behavior characteristics } \\
\hline \multirow{3}{*}{ Traffic light status } & $\begin{array}{c}\text { The middle stage of the red } \\
\text { light }\end{array}$ & 一 & $23 \%$ & $\begin{array}{c}-1.36^{* *} \\
(0.29)\end{array}$ & $-23 \%$ & $\begin{array}{c}-1.67^{* * *} \\
(0.14)\end{array}$ & $-16 \%$ \\
\hline & The late stage of the red light & $\begin{array}{c}1.43^{* * *} \\
(0.36)\end{array}$ & $53 \%$ & - & $-15 \%$ & - & $-15 \%$ \\
\hline & Std. dev. & $\begin{array}{c}1.26^{* * *} \\
(0.29)\end{array}$ & - & - & - & - & 一 \\
\hline Waiting position & Unreasonable position & - & $-32 \%$ & $2.42^{* * *}(0.31)$ & $52 \%$ & $3.43^{* * *}(0.38)$ & $35 \%$ \\
\hline \multicolumn{8}{|l|}{ Signalized intersection characteristics } \\
\hline Traffic light type & Countdown signal & $0.56^{* *}(0.21)$ & $-5 \%$ & $\begin{array}{c}-0.31^{* *} \\
(0.15)\end{array}$ & $3 \%$ & - & $3 \%$ \\
\hline Crossing length & - & - & $9 \%$ & $0.07^{* *}(0.02)$ & $9 \%$ & $\begin{array}{c}-0.04^{* * *} \\
(0.01)\end{array}$ & $-12 \%$ \\
\hline \multicolumn{8}{|l|}{ Traffic environment } \\
\hline The traffic volume & - & $\begin{array}{c}0.15^{* * *} \\
(0.12)\end{array}$ & $2 \%$ & - & $2 \%$ & - & $-4 \%$ \\
\hline $\begin{array}{l}\text { No. of individuals waiting upon } \\
\text { arrival }\end{array}$ & - & - & $-4 \%$ & - & $3 \%$ & $\begin{array}{c}-0.12^{* * *} \\
(0.18)\end{array}$ & $-4 \%$ \\
\hline \multirow[t]{2}{*}{ Time of day } & Afternoon & $\begin{array}{c}0.49^{* * *} \\
(0.23)\end{array}$ & $16 \%$ & - & $-4 \%$ & - & $-4 \%$ \\
\hline & e-bike type $\times$ age & - & $34 \%$ & - & $34 \%$ & $-0.46^{* *}(0.22)$ & $-21 \%$ \\
\hline \multirow[t]{2}{*}{ Interaction term } & e-bike type $\times$ time of day & $\begin{array}{c}0.62^{* * *} \\
(0.17)\end{array}$ & $58 \%$ & - & $-12 \%$ & - & $-12 \%$ \\
\hline & e-bike type $\times$ waiting position & - & $-6 \%$ & 一 & $15 \%$ & $0.43^{* *}(0.14)$ & $15 \%$ \\
\hline
\end{tabular}

The symbols ${ }^{*},{ }^{* *}$, and ${ }^{* * *}$ indicate significance at $10 \%, 5 \%$, and $1 \%$ levels, respectively. 
put forward to reduce e-bike riders' illegal crossing behaviors. For example, traffic management departments can increase the enforcement efforts of traffic police, especially at noon. Traffic warden (such as community volunteers) can also be arranged to regulate unreasonable position waiting. Besides, off-site enforcement facilities, as an emerging technology to curb nonmotorized vehicle violations, seem to be a trend in urban traffic management. However, traffic managers often hesitate in the use of traditional management measures (e.g., increasing the intensity of traffic police on duty) or emerging technical means (e.g., off-site law enforcement equipment) mainly because of the limited funds and unclear long-term law enforcement effect. Therefore, it is necessary to evaluate the implementation effects of the above interventions and policies in the future studies. In addition, regarding DEB riders, it is necessary to jointly enforce the law for the traffic management departments and delivery platforms, strengthen the publicity and education of traffic safety, and improve DEB riders' safety awareness, especially young riders. All in all, the illegal crossing behaviors not only affect their travel safety but also endanger the construction of urban civilization. Improving the traffic rule compliance rate of people is mutually beneficial for individuals, managers, and the whole society. Finally, future studies may need to analyze the impact of different interventions on improving traffic safety of e-bike riders at signalized intersections.

\section{Conclusions}

This study developed a security model for urban e-bike rider mixed groups' street-crossing decision-making at signalized intersections. The random parameter multinomial logit models considering interaction terms were applied for modeling three kinds of crossing behavior of e-bike rider mixed groups. Data were collected from five crosswalks at four intersections in Xi'an, China, with 4,180 samples collected over 20 hours. The random parameter logit model was used to account for unobserved heterogeneity effects by adding the random parameter items, which followed the normal distribution to the ordinary multinomial logit model. Moreover, the interaction between the type of e-bike and other influencing factors was considered to further illustrate the role of delivery e-bikes in urban e-bike rider mixed groups' crossing behaviors. In particular, when DEB riders interact with young attributes, noon time, and unreasonable waiting position variables, the possibility of running red lights immediately increases. Finally, we put forward targeted interventions to reduce the incidence of illegal crossings by e-bike riders.

There are several limitations that should be done in future work. Crossing behavior, a psychological process produced by the interaction of the internal individual characteristics and the external real-time traffic environment, although can be revealed partly through the overt behavior, in fact is different from real behavior [35]. This study only analyzes the influence of the individual properties and the external environment on e-bike riders' crossing behavior decision-making (go straight crossing) and without considering the left-turn crossing due to the limitation of the video field vision. Therefore, further experiments or investigations are needed to distinguish the information processing and potential errors on the risk perception attitude to systematically understand the mechanisms underlying e-bike riders' crossing behavior at signalized intersections. In addition, future research can use the platform based on automatic video collection and expand the range of data collection of e-bike street crossing samples to verify the transferability of model results.

\section{Data Availability}

Some or all data that support the findings of this study are available from the corresponding author upon reasonable request.

\section{Conflicts of Interest}

The authors declare that there are no conflicts of interest regarding the publication of this paper.

\section{Acknowledgments}

This research was funded by the National Key R\&D Program of China (grant numbers 2018YFE0120100 and 2018YFB1600900).

\section{References}

[1] X. Gao, J. Zhao, and H. Gao, "Red-light running behavior of delivery-service E-cyclists based on survival analysis," Traffic Injury Prevention, vol. 21, no. 8, pp. 558-562, 2020.

[2] Y. Guo, P. Liu, L. Bai, C. Xu, and J. Chen, "Red light running behavior of electric bicycles at signalized intersections in China," Transportation Research Record: Journal of the Transportation Research Board, vol. 2468, no. 1, pp. 28-37, 2014.

[3] Y. Guo, Z. Li, Y. Wu, and C. Xu, "Exploring unobserved heterogeneity in bicyclists' red-light running behaviors at different crossing facilities," Accident Analysis \& Prevention, vol. 115, pp. 118-127, 2018.

[4] L. Bai, P. Liu, Y. Chen, X. Zhang, and W. Wang, "Comparative analysis of the safety effects of electric bikes at signalized intersections," Transportation Research Part D: Transport and Environment, vol. 20, pp. 48-54, 2013.

[5] L. Bai, P. Liu, Y. Guo et al., "Comparative analysis of risky behaviors of electric bicycles at signalized intersections," Traffic Injury Prevention, vol. 16, no. 4, pp. 424-428, 2015.

[6] T. Tang, H. Wang, X. Zhou, and H. Gong, "Understanding electric bikers' red-light running behavior: predictive utility of theory of planned behavior vs prototype willingness model," Journal of Advanced Transportation, vol. 2020, Article ID 7097302, 13 pages, 2020.

[7] T. Tang, H. Wang, J. Ma, and X. Zhou, "Analysis of crossing behavior and violations of electric bikers at signalized intersections," Journal of Advanced Transportation, vol. 2020, Article ID 3594963, 14 pages, 2020.

[8] X. Shen, F. Zhang, H. Lv, S. Wei, and Z. Sun, "The application and extension of the theory of planned behavior to an analysis of delivery riders' red-light running behavior in China," 
Accident Analysis \& Prevention, vol. 144, Article ID 105640, 2020.

[9] Y. Zhang, Y. Huang, Y. Wang, and T. W. Casey, "Who uses a mobile phone while driving for food delivery? The role of personality, risk perception, and driving self-efficacy," Journal of Safety Research, vol. 73, pp. 69-80, 2020.

[10] F. Zhang, Y. Ji, H. Lv, and X. Ma, "Analysis of factors influencing delivery e-bikes' red-light running behavior: a correlated mixed binary logit approach," Accident Analysis \& Prevention, vol. 152, Article ID 105977, 2021.

[11] H. Wang, "A solution for the takeaway rider," 2020, https:// www.huxiu.com/article/385298.html.

[12] F. Zhang, H. Lyu, X. Shen et al., "Study on takeaway deliverers' red light running behavior based on planned behavior theory," China Safety Science Journal, vol. 29, pp. 1-6, 2019.

[13] C.-W. Pai and R.-C. Jou, "Cyclists' red-light running behaviours: an examination of risk-taking, opportunistic, and law-obeying behaviours," Accident Analysis \& Prevention, vol. 62, pp. 191-198, 2014.

[14] D. Zhu, N. N. Sze, and L. Bai, "Roles of personal and environmental factors in the red light running propensity of pedestrian: case study at the urban crosswalks," Transportation Research Part F: Traffic Psychology and Behaviour, vol. 76, pp. 47-58, 2021.

[15] F. Fraboni, V. Marín Puchades, M. De Angelis, L. Pietrantoni, and G. Prati, "Red-light running behavior of cyclists in Italy: an observational study," Accident Analysis \& Prevention, vol. 120, pp. 219-232, 2018.

[16] T. Campisi, G. Tesoriere, A. Canale et al., "Comparison of redlight running (RLR) and yellow-light running (YLR) traffic violations in the cities of enna and thessaloniki," Transportation Research Procedia, vol. 45, pp. 947-954, 2020.

[17] X. Yang, M. Huan, M. Abdel-Aty, Y. Peng, and Z. Gao, “A hazard-based duration model for analyzing crossing behavior of cyclists and electric bike riders at signalized intersections," Accident Analysis \& Prevention, vol. 74, pp. 33-41, 2015.

[18] X. Yang, M. Abdel-Aty, M. Huan, B. Jia, and Y. Peng, "The effects of traffic wardens on the red-light infringement behavior of vulnerable road users," Transportation Research Part F: Traffic Psychology and Behaviour, vol. 37, pp. 52-63, 2016.

[19] H. Yang, X. Liu, F. Su, C. Cherry, Y. Liu, and Y. Li, "Predicting e-bike users' intention to run the red light: an application and extension of the theory of planned behavior," Transportation Research Part F: Traffic Psychology and Behaviour, vol. 58, pp. 282-291, 2018.

[20] L. Bai and N. N. Sze, "Red light running behavior of bicyclists in urban area: effects of bicycle type and bicycle group size," Travel Behaviour and Society, vol. 21, pp. 226-234, 2020.

[21] K. Schleinitz, T. Petzoldt, S. Kröling, T. Gehlert, and S. Mach, "(E-) cyclists running the red light-the influence of bicycle type and infrastructure characteristics on red light violations," Accident Analysis \& Prevention, vol. 122, pp. 99-107, 2019.

[22] C. Wu, L. Yao, and K. Zhang, "The red-light running behavior of electric bike riders and cyclists at urban intersections in China: an observational study," Accident Analysis \& Prevention, vol. 49, pp. 186-192, 2012.

[23] T. Wang, S. Xie, X. Ye, X. Yan, J. Chen, and W. Li, “Analyzing E-bikers' risky riding behaviors, safety attitudes, risk perception, and riding confidence with the structural equation model," International Journal of Environmental Research and Public Health, vol. 17, no. 13, pp. 4763-4817, 2020.

[24] M. Johnson, J. Charlton, J. Oxley, and S. Newstead, "Why do cyclists infringe at red lights? An investigation of Australian cyclists' reasons for red light infringement," Accident Analysis \& Prevention, vol. 50, pp. 840-847, 2013.

[25] R. Yu, H. Zhao, C. Zhang, and Z. Wang, "Analysis of risktaking behaviors of electric bicycle riders in response to pedestrian countdown signal devices," Traffic Injury Prevention, vol. 20, no. 2, pp. 182-188, 2019.

[26] M. M. Abdul Manan, N. Mohamad Khaidir, and H. Mohamed Jamil, "Factors associated with red-light running among motorcyclists at signalised junctions in Malaysia," Transportation Research Part F: Traffic Psychology and Behaviour, vol. 73, pp. 470-487, 2020.

[27] D. Mukherjee and S. Mitra, "A comparative study of safe and unsafe signalized intersections from the view point of pedestrian behavior and perception," Accident Analysis \& Prevention, vol. 132, Article ID 105218, 2019.

[28] W. Wang, Z. Yuan, Y. Liu, X. Yang, and Y. Yang, “A random parameter logit model of immediate red-light running behavior of pedestrians and cyclists at major-major intersections," Journal of Advanced Transportation, vol. 2019, Article ID 2345903, 13 pages, 2019.

[29] S. Washington, M. G. Karlaftis, F. Mannering, and P. Anastasopoulos, Statistical and Econometric Methods for Transportation Data Analysis, CRC Press, Boca Raton, FL, USA, 2nd edition, 2011.

[30] A. Pervez, J. Lee, and H. Huang, "Identifying factors contributing to the motorcycle crash severity in Pakistan," Journal of Advanced Transportation, vol. 2021, Article ID 6636130, 10 pages, 2021

[31] S. Washington, M. G. Karlaftis, F. Mannering, and P. Anastasopoulos, Statistical and Econometric Methods for Transportation Data Analysis, CRC Press, Boca Raton, FL, USA, 2020.

[32] C. R. Bhat, "Simulation estimation of mixed discrete choice models using randomized and scrambled Halton sequences," Transportation Research Part B: Methodological, vol. 37, no. 9, pp. 837-855, 2003.

[33] R. Yu, Y. Xiong, and M. Abdel-Aty, “A correlated random parameter approach to investigate the effects of weather conditions on crash risk for a mountainous freeway," Transportation Research Part C: Emerging Technologies, vol. 50, pp. 68-77, 2015.

[34] W. Zhang, C. Zhou, W. Huang et al., "Investigating factors affecting riders' behaviors of occupying motorized vehicle lanes on urban streets," Accident Analysis \& Prevention, vol. 122, pp. 127-133, 2019.

[35] X. Zhuang, C. Wu, and S. Ma, "Cross or wait? Pedestrian decision making during clearance phase at signalized intersections," Accident Analysis \& Prevention, vol. 111, pp. 115124, 2018. 